\title{
Formation of ovarian follicles in ruminants
}

\author{
Jennifer L. Juengel*1 and Peter Smith ${ }^{1,2}$ \\ ${ }^{1}$ AgResearch Centre for Reproduction and Genomics, AgResearch, Invermay Agricultural Centre, \\ Puddle Alley, Private Bag 50034, Mosgiel 9053, New Zealand; ${ }^{2}$ Department of Anatomy, University \\ of Otago, PO Box 56, Dunedin 9054, New Zealand
}

\begin{abstract}
Summary
The ovarian follicle is a key component for determining a female's reproductive potential; however, the mechanisms regarding the factors that control formation of follicles are not well understood. Within a species, the number of follicles formed in the ovary can vary considerably among individuals. While we are beginning to better characterize the processes required for follicle formation, much still needs to be determined regarding the factors that control these processes. It is clear that both genetic and environmental factors influence the formation of the follicles and number of follicles formed; but the identity and relative role of many of these factors is still unknown. Furthermore, the relationships between events occurring during follicle formation and the animal's future reproductive potential are just beginning to be explored. In this review, we have focused on the process of follicle formation in domestic ruminants, using the sheep and cow as models. We first describe the events during ovarian formation leading up to and including follicle formation and then explore a few factors that may control these processes.
\end{abstract}

\section{Introduction}

The ovarian follicle is a key component in determining a female's reproductive potential. Not only does it contain the female germ cell, the oocyte; cells of the ovarian follicle also produce hormones necessary for the co-ordination of the reproductive cycle. Steroids and proteins produced by the follicle regulate secretion of the gonadotropins, and preparation of the oviduct and uterus to facilitate fertilisation of the oocyte and subsequent embryo development. In domestic ruminants, these hormones also control the timing of mating and ovulation to optimise fertilisation of the matured oocyte.

While it is clear that a failure to undergo normal follicular formation, such as occurs in freemartins (i.e. a condition that occurs in most female calves born twin to a male calf), results in reproductive failure (Padula 2005), recent data in cows also supports the hypothesis that much more subtle differences in regulation of formation of ovarian follicles are linked to alterations in reproductive performance. Cows with a decreased number of antral follicles, which is related 
to a reduced total number of morphologically healthy follicles (ovarian reserve), have been shown to have lower fertility than cows with a higher number of antral follicles (Cushman et al. 2009, Evans et al. 2012, Mossa et al. 2012). This suggests events occurring during fetal life, when the ovarian reserve is established, have the potential to affect the animal's lifetime reproductive performance.

Understanding the developmental source of the cells that comprise the ovarian follicle may also provide insights into regulation of follicular function. The concept that the granulosa cells are derived from cells at the surface of the ovary, as shown in sheep over a decade ago (Sawyer et al. 2002), is now accepted for other mammalian species (Burkhart et al. 2010, Garverick et al. 2010, Mork et al. 2012, Hummitzsch et al. 2013). However, recent research has highlighted that these cells may not be "classical" surface epithelia cells (Hummitzsch et al. 2013). The source of the cells that contribute to the theca layer of the follicle is still uncertain. It is clear that cells from the mesonephros migrate into the ovary and form structures such as the cell streams and rete ovarii, but whether these are sources of the theca cells remains uncertain (Juengel et al. 2002). Furthermore how these cells may influence growth and development of the follicle is an area of increasing interest (Smith et al. 2009).

Even though the ovarian follicle and factors controlling its formation are key for determining female reproductive potential, there is a paucity of information regarding the control of follicle formation. The aim of this review is to provide an overview of the timing of key developmental events of ovarian follicular formation, the potential factors regulating these key processes and how we might better control these processes to improve reproductive performance in domestic ruminants. Some areas of potential future research are also highlighted. The review focuses on the two domestic ruminants most intensively studied, the sheep and the cow, to provide a framework for discussion.

\section{Ovarian development}

\section{Timeline of events}

There are multiple key events necessary for formation of the follicle, all of which occur during fetal life in sheep and cattle. These occur in a sequential order but many overlap each other. Key processes include migration of the germ cells from the yolk sac to the gonadal ridge, formation of the gonadal ridge, proliferation of germ cells, migration of cells from the mesonephros, formation of ovigerous cords containing the germ cells and pregranulosa cells, initiation of meiosis, germ cell atresia, formation of the follicle, initiation of follicular growth, recruitment of theca cells and development of antral follicles. A schematic of timeline of events during ovarian development in sheep and cattle is presented in Fig. 1.

\section{Migration of germ cells and gonadal ridge formation}

On day 23-24 of fetal life in sheep, the coelomic epithelium on the medial aspect of the mesonephros begins to thicken and is the first evidence of the undifferentiated gonad (Juengel et al. 2002). In cattle, these events occur around day 27-32 (Erickson 1966, Wrobel \& Suss 1998). In both species, primordial germ cells are evident from around the time of gonadal ridge formation. In fact, extragonadal primordial germ cells can be recognised very early in development, from day 18 in cattle (Wrobel \& Suss 1998). Migration of primordial germ cells to the genital ridge is observed between days 18 and 23 in sheep (Juengel et al. 2002). 


\section{Approximate \\ Day of Fetal Life}

\begin{tabular}{|c|c|c|}
\hline Cow & Sheep & \\
\hline $27-32$ & 23-24 & $\begin{array}{l}\text { Gonadal ridge evident, } \\
\text { Germ cells mitotically active }\end{array}$ \\
\hline $39-45$ & $32-35$ & $\begin{array}{l}\text { Gonadal sex differentiation, } \\
\text { Steroidogenesis initiated }\end{array}$ \\
\hline 60 & 45 & Ovigerous cord evident \\
\hline $75-80$ & 55 & Germ cell meiosis initiated \\
\hline $80-90$ & $55-60$ & Germ cell apoptosis initiated \\
\hline $90-100$ & 75 & First follicles formed \\
\hline $130-140$ & $90-100$ & First follicles growing \\
\hline 150 & $100+$ & Germ cell meiosis ends \\
\hline 150 & 100 & $\begin{array}{l}\text { Ovigerous cords close to } \\
\text { surface epithelieum }\end{array}$ \\
\hline 170 & $100-110$ & $\begin{array}{l}\text { Most follicles formed, } \\
\text { Ovigerous cords mostly dissolved }\end{array}$ \\
\hline 282 & 148 & Birth \\
\hline
\end{tabular}
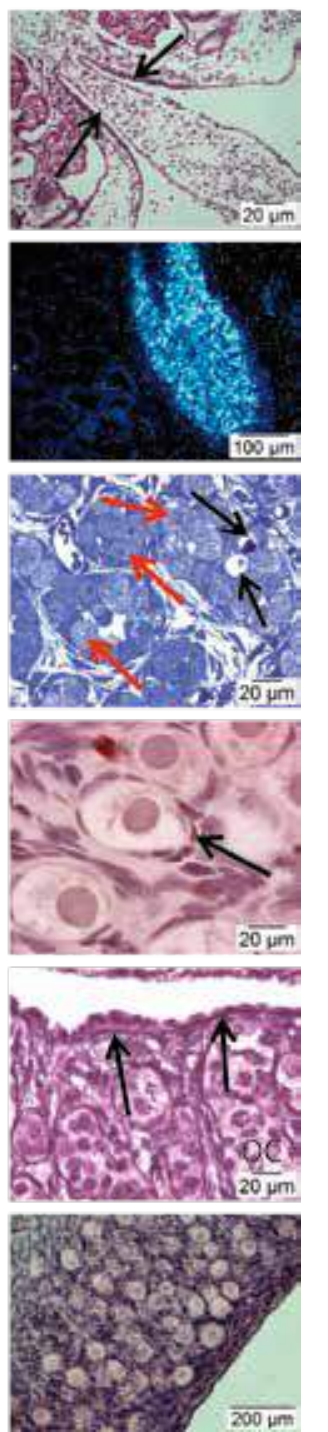

Fig. 1. Time sequence of key developmental events occurring during ovarian development and formation of follicles in sheep (Reynaud \& Driancourt 2000, Quirke et al. 2001, Juengel et al. 2002, Sawyer et al. 2002) and cattle (Erickson 1966, Dominguez et al. 1988, Wrobel \& Suss 1998, Burkhart et al. 2010, Garverick et al. 2010, Hummitzsch et al. 2013). Timeline for key events in cattle and sheep are given on left. Photomicrographs on right depict from top 1) gonadal ridge evident on day 24 in sheep (arrows); 2) widespread expression of HSD3B1 mRNA in day 32 sheep ovary; 3 ) meiotic (red arrow) and apoptotic (black arrow) germ cells present in day 55 sheep ovary; 4) growing follicle (dividing cell labelled with BrdU; arrow) with other non-growing type 1/1a follicles in a day 90 sheep ovary; 5) Periodic Acid Methionine Schiff staining of a day 95 sheep ovary showing the basement membrane (arrows) forming between ovigerous cords (OC) and surface epithelium thus closing the cord; and 6) numerous formed and growing follicles with ovigerous cords mostly dissolved in this day 120 sheep ovary. 
Germ cell numbers: Mitosis, meiosis and atresia of germ cells

The change in number of germ cells is controlled by the balance between germ cell mitosis and atresia. In both the bovine and ovine ovary, germ cells present in the developing ovary during ovarian formation are mitotically active (Wrobel \& Suss 1998, Juengel et al. 2002). In the early stages of ovarian development, mitosis predominates. In sheep meiosis begins around day 55 with oocytes in prophase of meiosis 1 observed, predominately in the medullary region of the ovary (Sawyer et al. 2002). Germ cell death is particularly high during meiosis and apoptotic germ cells can be observed shortly following the onset of meiosis (Reynaud \& Driancourt 2000). Germ cells continue to enter into meiosis past day 100 of gestation (Juengel et al. 2002). In cattle, meiosis is initiated around day 75-80 and by around day 150 of gestation, germ cells are no longer entering meiosis (Erickson 1966).

In cattle, more in depth studies focused on understanding the pattern of germ cell proliferation have shown that, between day 50 (first day studied) and 60 of gestation, germ cell numbers increased 20 fold with the number of mitotic figures (proliferative cells) showing a similar increase, and this seems to be the stage of greatest proliferation (Erickson 1966). Germ cell proliferation remains at a relatively high rate to day 110 with a sharp drop in proliferation between days 110-150, after which proliferating germ cells are not observed. The number of germ cells peaks at around 2.7 million on day 110 of gestation (Erickson 1966). By day 90, large numbers of apoptotic germ cells can be observed within the ovigerous cord and attrition of oocytes through apoptosis continues to occur through to day 250 of gestation (Erickson 1966, Burkhart et al. 2010, Garverick et al. 2010). A long sustained wave of atresia can be observed between days $80-190$ with $>25 \%$ of germ cells showing morphological signs of dying during this time. Just before birth, the numbers of oocytes observed had dropped to around 60,000 (Erickson 1966).

In sheep, germ cell numbers increase over 13 fold between days 40 and 55 of gestation, peak at day 75 (around 1 million) and fall sharply by day 90 (Smith et al. 1993). Prior to day 75, mitosis is the dominant factor but from day 75, a massive wave of germ cell atresia is observed. Thus while mitosis of germ cells is still observed out to day 100, the number of germ cells at day 90 is $15 \%$ of that observed on day 75 and falls to around 65,000 at day 135 of gestation shortly before birth (Smith et al. 1993).

\section{Migration of cells from the mesonephros}

The mesonephros is a major source of cells for the developing ovary in both sheep and cows (Sawyer et al. 2002, Burkhart et al. 2010, Garverick et al. 2010) although mesonephric cells are unlikely to be the origin of cells comprising the primordial follicles (Sawyer et al. 2002, Hummitzsch et al. 2013). Sources of these mesonephric cells include the mesenchymal cells and mesangial and epithelial cells of the glomeruli as well as epithelial cells of the tubular network of the regressing mesonephros.

The migration of cells from the mesonephros into the developing ovary has been more thoroughly defined in sheep (McNatty et al. 2000, Juengel et al. 2002) than in cattle. From day 25 of gestation, mesenchymal cells can be seen migrating into the developing ovary. These are closely followed by mesangial cells (day 26) and then epithelial cells of the glomerulus. Originally these three cell types enter the ovary in a relatively undefined pattern but later the migration of the mesangial and epithelial cells of the glomeruli appears more organized with a distinct streaming pattern, thus giving these structures the name cell streams which can be observed from day 40. Epithelium from the tubules and glomerulii of the mesonephros are also 
thought to contribute to the rete cell masses and tubules observed in the developing ovary. These masses are often bound by basement membrane although this membrane can be discontinuous with cells appearing to be streaming out through gaps in the membrane.

A similar pattern of cell migration from the mesonephros to the ovary has been observed in cattle (Burkhart et al. 2010, Garverick et al. 2010). The mesonephros was prominent in day 45 fetuses with "cell streams" observed by day 60 of gestation. By day 90 of gestation the cells streams were well defined, but mainly located in the medullary region of the ovary. A massive flow of cells from the mesonephros continues through to at least day 105 . The rete is discernible at day 105 of gestation with rete tubules appearing first followed by large rete masses observable from day 170 onward.

\section{Formation of ovigerous cords}

Ovigerous cords are the structures within the developing ovary that contain the germ cells and associated pregranulosa cells (Fig. 2). They are sometimes called germ cell nests but serial sectioning of the ovary indicates a cord-like structure with a somewhat tortuous nature. In sheep, by day 38, pregranulosa cells have made physical contact with oogonia but are still assembling into the ovigerous cords (Sawyer et al. 2002). Patches of basal lamina, which is in contact with the surrounding extracellular matrix, can be observed on the surface of the plasma membrane of the pregranulosa cells. As the ovigerous cords develop, the basal lamina becomes continuous, thus isolating the germ cells and the pregranulosa cells from the surrounding cell types in the developing ovary. The exception to this is at the surface of the ovary where the cords are open and thus in contact with cells at the surface (Sawyer et al. 2002). The separation of germ cells and pregranulosa cells in ovigerous cords from the surrounding stroma occurs by day 45 in sheep. In cattle, by day 60 initial formation of ovigerous cords has been observed with formation well progressed into the periphery of the ovary by day 75 (Garverick et al. 2010). It should be noted that a small number of germ cells do not get incorporated into the ovigerous cords and can be observed, often in small groups, in the medulla of the ovary throughout the process of formation of the follicles. These germ cells, which have been termed medullary germ cells, do not participate in the normal follicular formation processes. However, they have been observed in association with rete cells and blood vessels. The fate of these germ cells, and their function, if any, is unknown (Sawyer et al. 2002).

A key question has been what is the developmental origin of the pregranulosa cells. A landmark paper by Sawyer et al. (2002) clearly demonstrates that the majority of granulosa cells in the newly formed ovine follicle were derived from epithelial cells at the surface of the ovary. Although not as thoroughly examined, later studies drew the same conclusions in cattle (Burkhart et al. 2010, Garverick et al. 2010), largely based on the similarity of developmental events and morphology observed between the developing sheep and cattle ovary. In both sheep and cattle, it was noted that during the time that the epithelial cells at the surface of the ovary were dividing and contributing to the population of pregranulosa cells in the ovigerous cord, the surface epithelium changed from a readily definable multi-layered structure to one much less defined, lacking a basement membrane. In fact in cattle, the surface epithelium was often difficult to clearly define in the ovary during ovarian follicle formation. It was only when the ovigerous cords closed to the surface, and thus were no longer being supplied with new pregranulosa cells, that the classical mature phenotype surface epithelium, with a well-defined basement membrane, was formed. Recent work (Hummitzsch et al. 2013) has examined this process in much greater detail in the developing bovine ovary. These researchers used markers of basal lamina to confirm that the ovigerous cords are always separated from cells in the stroma 
Day 38

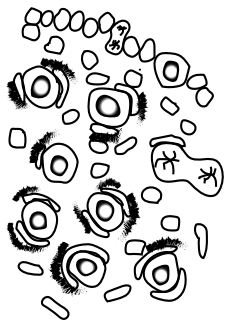

Day 75

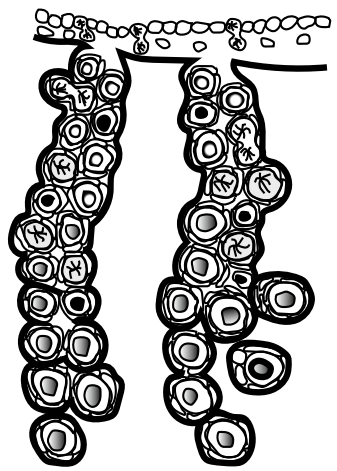

Day 45

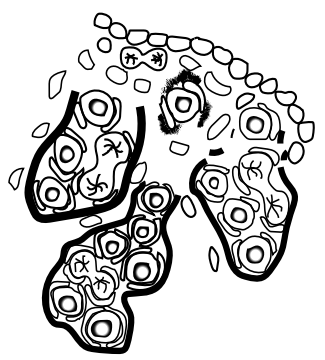

Day 90

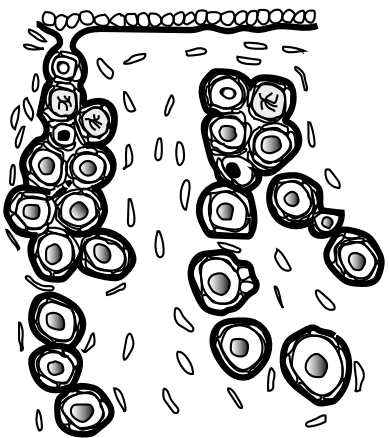

Day 55

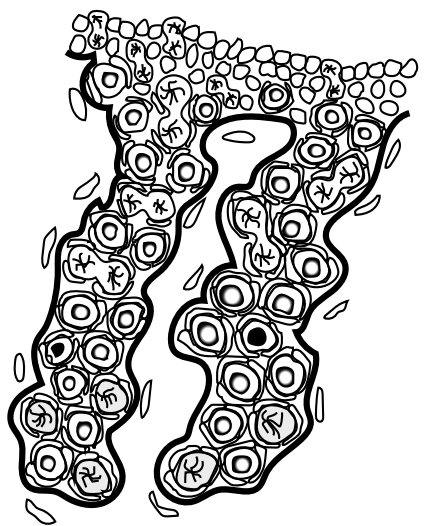

Day 100

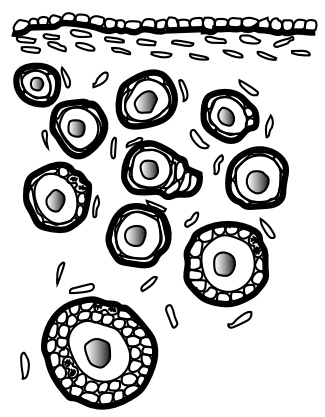

Oogonia

Apoptotic germ cell

Meiotic germ cell

Oocyte

Mitotic cell

Basal Lamina

Basal lamina

(developing)
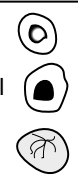

(O)

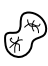

$\sim$

Fig. 2. Schematic diagram of events occurring during formation of the ovigerous cords, subsequent dissolution of the ovigerous cords and formation of ovarian follicles. The timeline refers to days of fetal life in sheep. By day 38 of fetal life, germ cells and pregranulosa cells are beginning to make contact and aggregate. Basement membrane is associated with the aggregating germ cells and pregranulosa cells and isolates them from the surrounding stroma by day 45 of fetal life. The ovigerous cords are open to the surface epithelium and additional pregranulosa cells are added to the ovigerous cords through proliferation of the cells at the surface of the ovary. Within the ovigerous cords, germ cells also undergo mitosis. Around day 55 of fetal life, germ cells begin to undergo meiosis and apoptosis of germ cells is observed soon after meiosis is initiated. The ovigerous cords begin to dissolve starting around day 75 of fetal life, as individual and small groups of oocytes and their associated granulosa cells begin to isolate themselves from the ovigerous cord (also see Fig. 3). By day 90, the ovigerous cords are becoming isolated from the surface of the ovary and a basal lamina forms under the surface epithelial cells. By day 100 a mature phenotype surface epithelium, resting on a basal lamina, is present, thus separating any remaining ovigerous cords from the surface epithelium. Formation of follicles starts at the medullary end of the ovigerous cords and proceeds towards the surface. By day 100, the dissolution of the ovigerous cords and formation of follicles has progressed considerably and small growing follicles can be observed in the ovary. The reader is referred to Sawyer et al. (2002) for photomicrographs of histological sections through the ovary at various times during ovarian development. 
by a basal lamina. In addition, they determined that the classical defined surface epithelium (i.e. sitting on a basal lamina) of the newly formed gonad is confined to the base of the ovary where it is connected to the mesonephros. They propose that cells they have termed gonadal ridge epithelial-like (GREL) are precursor cells for both the granulosa cells and the surface epithelium of the adult ovary. Given the description of the surface epithelium of the earlier studies in sheep and cattle, i.e. much less defined and lacking a basement membrane until the ovigerous cords are closed, it seems likely that the surface epithelial cells described by Sawyer et al. (2002), Burkhart et al. (2010) and Garverick et al. (2010) are the same as the GREL cells described by Hummitzsch et al. (2013). This confirmed a common precursor cell for both the cells of the surface epithelium of the ovary and the granulosa cells in both sheep and cattle. The recent work by Hummitzsch et al. (2013) has also raised the question of whether the developmental pathway of the surface epithelium of the adult ovary differs from the developmental pathway of the mesothelial cells lining the peritoneal cavity and other peritoneal organs.

Given the separation between the germ cells and pregranulosa cells in the ovigerous cords, and the cells in the stroma, a key question is what role the stroma plays in ovarian formation. As indicated above, large numbers of cells migrate into the ovarian stroma from the mesonephros. The cell streams have been observed in close approximation to the developing ovarian vasculature thus it has been hypothesised that these cells are using the vasculature as a pathway and/or are involved in the development of the vasculature network (Juengel et al. 2002, Sawyer et al. 2002). They have also been postulated to be precursor cells for the theca interna of the growing follicle (Juengel et al. 2002). Hummitzsch et al. (2013) have recently proposed that the stroma takes an active role in forming or compartmentalizing the ovigerous cords, surface epithelium and follicles, penetrating to separate structures from each other and breaking down the ovigerous cords into individual follicles.

Eventually, a basement membrane is formed between the pregranulosa cells and germ cells in the ovigerous cords, and the surface epithelium. When this is complete the cord is considered closed to the surface epithelium and the surface epithelium obtains a mature ovary phenotype (Sawyer et al. 2002, Hummitzsch et al. 2013). This process starts by day 75 in sheep and is completed by day 100. In cattle, closure of the ovigerous cords to the surface epithelium starts around day 130 and is complete by about day 150 (Burkhart et al. 2010). Recent studies have examined the components of the basal lamina surrounding the ovigerous cords, the newly formed follicle and underlying the surface epithelium of the ovary. The basal lamina of these structures was very similar with all containing Laminin 111, Collagen type IV and XVIII, heparan sulfate proteoglycan 2 (Perlecan) and Nidogen 1 and 2 (Hummitzsch et al. 2013).

Often within an ovigerous cord, germ cells at differing stages of development can be observed. For example at day 75 in sheep (McNatty et al. 2000, Sawyer et al. 2002) and day 105-110 in cattle (Burkhart et al. 2010, Garverick et al. 2010), the germ cells at the surface of the ovary are still mitotically active. Moving through the cortex towards the medulla, germ cells in meiosis or undergoing apoptosis becomes the predominate feature, whereas at the interface between the cortex and medulla of the ovary, type 1/1a (primordial/transitional) follicles are present. What drives this apparent gradient of developmental progress is unknown. It could be hypothesised that the association between the germ cells and the pregranulosa/GREL cells sets in motion a developmental programme for the forming follicles. As new GREL cells are added to the ovigerous cord from the surface of the ovary and begin associating with the dividing germ cells, those that formed this association could be pushed further into the cord and thus represent more mature germ cells progressing along a developmental pathway towards either death or formation into a follicle. Alternatively these developmental events could be under the control of paracrine factors secreted by cell streams initially and subsequently rete cells as they progressively populate the spaces between cords in a medullary-cortical direction. An additional feature of cattle ovaries 
described in Burkhart et al. (2010) and Garverick et al. (2010) was the lobular nature of the ovary until day 210, which was also associated with varying stages of development, although the lobular nature was not reported in several other studies nor has it been observed in sheep. The role, if any, of the lobular nature of the ovary is unknown.

\section{Formation of the follicle}

In sheep the first follicles formed (type 1 or primordial) can be observed from about day 75 (Sawyer et al. 2002) whereas this occurs slightly later, around day 90-100 in the cow although one study observed follicle formation even earlier around day 75 (Tanaka et al. 2001). In both the sheep and the cow, the first follicles to form are at the base of the ovigerous cords furthest from the surface of the ovary in the inner cortex (McNatty et al. 2000, Sawyer et al. 2002, Burkhart et al. 2010, Hummitzsch et al. 2013).

The signal, if there is one, that causes a single oocyte and its accompanying granulosa cells to isolate from the other oocytes and granulosa cells within the ovigerous cord is not known. However, it is clear that increasing amounts of basal lamina are synthesized causing dissolution of the ovigerous cord and formation of isolated fully formed follicles (Fig. 3). Often an intermediate step, which appears as isolation of a few germ cells with their associated granulosa cells from the main ovigerous cord, is observed. These are often referred to as nests of forming follicles. Further division of these structures by the developing basal lamina results in the formation of discrete follicles. Hummitzsch et al. (2013) have proposed an active role for the stroma in causing dissolution of the ovigerous cords and formation of the ovarian follicles. They propose that the stroma penetrates the ovigerous cord, dividing them into smaller groups of germ cells and finally formed follicles. An alternative explanation is that the pregranulosa/ GREL cells secrete increasing amounts of basal lamina, which causes the isolation of first groups and then individual follicles. The apparent separation of individual follicles in the internal portions of the "nest" of forming follicles, which are still isolated from the ovarian stroma, by a discrete basal lamina might support a model of follicle formation more driven by the oocyte/ pregranulosa cell complexes themselves versus a more active role of the stroma (Juengel et al. 2002, Sawyer et al. 2002). However, further work is needed to better define the process of formation of individual follicles.

In sheep, it is clear that follicles can form either as an oocyte surrounded by a single layer of flattened granulosa cells (type 1), or a single layer of mixed flattened and cuboidal cells (type 1a). There is also a high degree of variability in the size of both the oocyte and follicle as well as the number of granulosa cells (Lundy et al. 1999). Oocyte size ranges from 22.8 to $53.0 \mu \mathrm{m}$ with size of the follicle ranging from 28.1 to $64.0 \mu \mathrm{m}$. The calculated number of granulosa cells in type 1 and 1a follicles ranged from 3 to 136 . The variability in the number of granulosa cells found in the type 1/1a follicles is thought to be related to the process of follicle formation. It has been noted that while a significant proportion of germ cells die during the process, the pregranulosa cells in the ovigerous cords do not undergo a similar wave of cell death. In fact, the pregranulosa cells associated with a dying germ cell remain healthy and seem to become associated with a remaining healthy germ cell. It is proposed that in this manner, surviving germ cells end up with varying numbers of granulosa cells depending on the local environment of the germ cell during the time of follicle formation (Sawyer et al. 2002). The increasing granulosa cell number associated with each oocyte may also contribute to the increased secretion of basal lamina leading to cord dissolution and follicle formation. The number of granulosa cells may also help determine the resulting shape they take. If fewer granulosa cells are present they may "stretch out" to surround the oocyte and have a flattened 


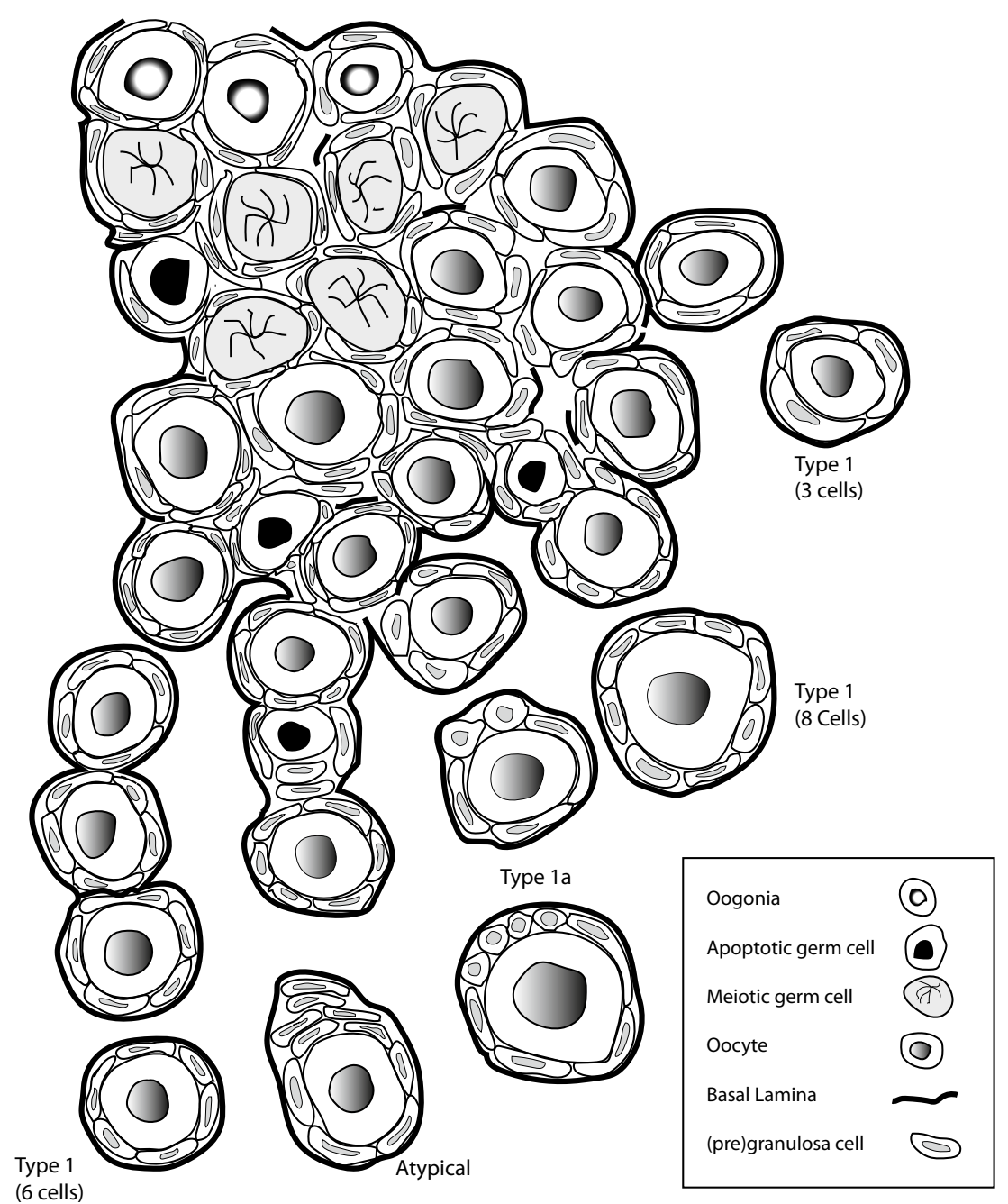

Fig. 3. Schematic diagram illustrating the process of formation of the follicles and how this process leads to variation in morphology of newly formed follicles. Starting around day 75 of fetal life in sheep (day 90-100 in cattle), individual or groups of oocytes and their associated granulosa cells begin to separate from the ovigerous cords. Follicles seem to form as both type 1 (single layer of flattened granulosa cells) and type 1a (single layer of granulosa cells of mixed phenotype i.e. both flattened and cuboidal). It has been hypothesised that the variation in newly formed follicles is, at least in part, related to the death of a large proportion of germ cells during development. Given that the pregranulosa cells associated with a dying germ cell remain healthy, following the death of the germ cell, these cells must be reassigned to other healthy germ cells. In this manner, developing healthy oocytes may recruit additional granulosa cells. Furthermore, in situations where a number of oocytes and their associated granulosa cells are isolated together and one of the oocytes die, an atypical follicle, with multiple layers of granulosa cells on one side could be developed with a remaining healthy oocyte. Readers are referred to Juengel et al. (2002) for micrographs of histological sections during the time of follicle formation in sheep.

phenotype whereas, when more are present, some may take a more cuboidal shape as each cell has less area to cover. This may also explain the presence of follicles with a "comet tail" shape, with a single layer of granulosa cells apparent on one side of the follicle but multiple layers, often in a comet tail shape, apparent on the other side (Sawyer et al. 2002). Whether these unusually shaped follicles are fully functional is unknown. 
In cattle, a similar pattern of massive germ cells atresia, without a coinciding loss of pregranulosa cells, was observed. Type 1 follicles were evident before type 1a follicles were observed. However, given the large number of type 1a follicles observed during ovarian development, as well as the similarity observed in variability in the size of the formed follicles, it is likely that follicles form as both type 1 and 1a follicles in cattle as well (Burkhart et al. 2010).

Initiation of follicular growth, recruitment of thecal cells and development of antral follicles

Initiation of follicular growth occurs shortly after follicle formation, with the first type 2, or primary follicle, defined as an oocyte surrounded by 1 but less than 2 complete layers of cuboidal granulosa cells, observed by day 90-100 in sheep (Juengel et al. 2002, Sawyer et al. 2002) and around day 130-140 in cattle (Dominguez et al. 1988, Fortune 2003, Burkhart et al. 2010). From this stage, follicles progress through development with antral follicles observed before birth, at around day 135 of gestation in sheep (Juengel et al. 2002) and by day 170-200 of gestation in cattle (Burkhart et al. 2010).

A key developmental event in growth of the ovarian follicle is recruitment of theca cells. This occurs early during follicle development (Young \& McNeilly 2010), clearly evident shortly after the follicles contain two complete layers of granulosa cells. Some authors have proposed that the theca cells are associated with the newly formed follicle, but difficult to identify with commonly used methods (Hirshfield 1991). In sheep, a proportion of type 2 follicles had discernible theca whereas theca was observed with all type 3 follicles (Lundy et al. 1999). Steroidogenic potential of the theca develops shortly thereafter, during the transition from the preantral to antral stage with some theca interna cells expressing key proteins for steroid synthesis at this time (Bao \& Garverick 1998, Logan et al. 2002). Vascularization of the follicle is another key function of the theca as the granulosa cells and oocyte are separated from the vascular network by their enclosing basement membrane. A key question regarding the source of the theca cells remains unanswered at this time. Given the steroidogenic nature of the cells of the cell streams/rete; these cells have been proposed as a potential source of the theca cells (Juengel et al. 2002). Additionally, association between the cell streams and the vascular network of the developing ovary has been observed. If the theca cells develop after follicular growth has been initiated, which occurs throughout the ewe or cow's life, it seems possible that there is a theca stem cell population within the ovary. Characterization of theca stem cells from rats has been published (Honda et al. 2007) and factors associated with stem cell niches have been identified in the theca externa, associated with large vessels in bovine follicles (Hatzirodos et al. 2012). The oocyte/granulosa cells could secrete factors that result in differentiation of ovarian stromal cells to theca cells (Young \& McNeilly 2010).) However, the factors which drive recruitment and development of these cells are not well understood.

\section{Factors regulating formation of the follicles}

Genetic models of gonadal hypoplasia

In multiple species, including sheep and cattle, gonadal hypoplasia can be observed in a small number of animals. Genetic causes for gonadal hypoplasia have also been identified. Sheep homozygous for inactivating mutations in either growth differentiation factor 9 (GDF9) or bone morphogenetic protein 15 (BMP15), which are related growth factors of the transforming growth factor beta (TGFB) superfamily produced by the oocyte, usually have small inactive ovaries (Juengel et al. 2013). However, for BMP15 at least, which is not expressed until after the follicle begins to 
grow in sheep, this defect is caused by a failure of normal follicular growth; and formation of the ovary and follicle are normal. The potential role for GDF9 is less clear. While normal follicular development does not occur in ewes homozygous for inactivating mutations in GDF9, in depth analysis of the numbers of follicles formed has not been undertaken. It is expressed in the oocyte before the follicle is formed (Juengel et al. 2004) and treatment with GDF9 promotes primordial follicle formation in the hamster (Wang \& Roy 2004). Furthermore, single gene polymorphisms in GDF9 are associated with the number of viable oocytes collected by ovum pick-up which could be consistent with a potential link between this gene and the number of follicles formed (Santos-Biase et al. 2012). However, immunization with GDF9 peptides also causes a reduction in the number of antral follicles in adult animals (Juengel et al. 2013), long after formation of the follicles has been completed. Other members of the TGFB superfamily may also be involved in follicular formation. Ewes with mutations in BMPR1B, which is a common type 1 receptor for multiple members of the BMP sub-family of growth factors, show some perturbations in follicular formation. Whether the number of follicles formed in ewes carrying the mutation (i.e. Booroola) differs is unclear as studies from two different laboratories found contradicting results (Smith et al. 1994, Ruoss et al. 2009). However, the receptors are expressed during development of the ovary, well before and continuing through follicle formation. Furthermore, morphological differences in primordial (type 1) follicles are noted suggesting that they are different from the beginning. This included the follicles being larger with greater volume of mitochondria and other cell organelles (Reader et al. 2012). A polymorphism in the BMPR2 gene, which acts as a receptor for both BMP15 and GDF9, as well as other members of the TGFB superfamily, has also been linked with the number of viable oocytes collected during ovum pick up in cattle, potentially indicating a role for members of the TGFB superfamily in regulating the number of follicles formed (Santos-Biase et al. 2012).

In cattle, hereditary gonadal hypoplasia, affecting both male and female animals, has been observed in Northern Finncattle and Swedish Mountain (also known as Swedish Highland) cattle. This autosomal recessive trait with incomplete penetrance (Eriksson 1943) was linked to impaired migration and proliferation of primordial germ cells (Settergren 1964). This trait is often unilateral, affecting the left ovary more frequently than the right ovary but can affect both gonads. If both gonads are affected, the animal is infertile. Recent genetic analysis has identified a copy number variation in the KIT gene as likely underlying this condition (Venhoranta et al. 2013).

In goats, the Polled Intersex Syndrome mutation results in a female to male sex reversal in females that are homozygous for the mutation. An $11.7 \mathrm{~kb}$ deletion in chromosome 1, affecting the transcription of FOXL2 and PISRT1, has been identified as triggering the intersexuality in these goats (Pailhoux et al. 2001a). Examination of the developing ovary in animals homozygous for the mutation indicates that ovarian development deviates from normal as early as day 36, with homozygous carriers of the deletion having decreased expression of mRNA encoding CYP19A1 and FOXL2 by day 36 and increased levels of SOX9 and AMH by day 40 (Pailhoux et al. 2001b, Pailhoux et al. 2002). At day 36, no morphological differences could be observed between normal and intersex females but by day 40 reduced cortex areas, and the formation of seminiferous cords and tunica albugineas were observed in the intersex females compared to normal females. Another feature in these intersex animals is the death of the germ cells from when they first start to enter meiosis on day 56 through to birth such that adults lack germ cells. While this intersex condition shares similarities with the freemartin syndrome (discussed below), the ontogeny of the condition differs with the sex reversal phenotype occurring much earlier in development in the intersex animal than freemartins. However, the exposure of the germ cells to $\mathrm{AMH}$ during the time of meiosis could be the underlying cause of germ cell death in both syndromes (Pailhoux et al. 2002). 
Additional studies with these intersex animals have identified down regulation of FOXL2 as most likely underlying the observed sex reversal (Pailhoux et al. 2001b, Pannetier et al. 2006, Boulanger et al. 2008). FOXL2 directly regulates CYP19A1 expression and thus the decreased CYP19A1 expression can be directly linked to down regulation of FOXL2. Through study of this interesting animal model, insights into the early steps of ovarian development are being gained (Baron et al. 2005).

\section{Nutritional and other environmental factors}

Maternal nutrition has also been linked to changes in the numbers of follicles formed in both sheep (Lea et al. 2006) and cattle (Evans et al. 2012, Mossa et al. 2013). In cattle, restriction of nutrition in the dam from shortly before conception through the first trimester resulted in reduced numbers of antral follicles and lower AMH concentrations in the female offspring (Mossa et al. 2013). Given the association between the number of antral follicles, $\mathrm{AMH}$, and total number of follicles (Ireland et al. 2009), this is consistent with reduced nutrition during ovarian formation resulting in reduced numbers of follicles forming. Similarly, cows with multiple readings for a high number of somatic cells in milk during gestation, indicative of chronic inflammation/ infection of the mammary gland, had female offspring with lower $\mathrm{AMH}$ concentrations at 12 months of age, also indicative of a reduced follicular reserve (Evans et al. 2012).

The effects of nutritional restriction during gestation on formation of ovarian follicles have also been studied in sheep. Reduction of nutrition from conception to day 50 of pregnancy resulted in a smaller ovary on day 50 of gestation for the female offspring. However, this difference was no longer observed by day 65 of gestation, suggesting a delay of early development. Similarly, germ cell numbers were not affected at day 65 of gestation although fewer germ cells had entered meiosis in fetuses from restricted dams (Rae et al. 2001). Restriction of nutrition through to day 95 of pregnancy led to a reduction of ovulation rate in the female offspring when they were 20 months of age through unknown mechanisms (Rae et al. 2002). A decrease in staining for Ki67, a marker of proliferation, was observed in germ cells at day 65 of gestation of nutritionally restricted fetuses (from conception to day 30 of gestation) compared to those on a maintenance diet (Lea et al. 2006). In addition, longer term restriction of nutrition (day 0-110) also resulted in increased expression of $B A X$, a proapoptotic marker, in the primordial follicles, potentially indicating an increased loss of germ cells after follicle formation in nutrient restricted animals (Lea et al. 2006). Nutritional restriction from day 28 to 78 also resulted in upregulation of proteins associated with response to oxidative base lesions (i.e.TP53, BCL2 and base-excision repair polymerase beta) without increasing the rate of apoptosis of the germ cells, potentially representing an up-regulation of cell cycle-inhibition to permit DNA repair, thereby allowing the germ cells to survive (Murdoch et al. 2003). This may be manifested as a delay in germ cell development discussed previously. Conditions leading to placental insufficiency, and thus restricted fetal nutrition, were also associated with fewer follicles (primarily affecting the primordial follicular pool) present on day 103 of gestation (Da Silva et al. 2003) and day 131 of gestation (Da Silva et al. 2002). Exposure of female fetuses to sewage sludge also reduced the number of follicles present on day 110 of gestation. A reduction in fetal weight was noted, indicative of possible restricted nutrition. However, the authors concluded that this restricted nutrition was most likely not a major factor in the observed differences in number of follicles observed with direct effect of compounds within the mixture on the developing ovary likely involved (Fowler et al. 2008). Exposure of pieces of ovarian cortex collected from bovine fetuses to genistein or octylphenol, but not bisphenol A, appeared to disrupt normal follicle formation resulting in fewer follicles in the ovarian cortex following culture (Fortune et al. 2013). 


\section{Steroids and other hormones}

A cause of gonadal hypoplasia in female cattle is developmental abnormalities that commonly occur in females born twin to a male (i.e. freemartin). This condition can also occur in female sheep born twin to males but it is quite rare. In freemartin animals, the reproductive tract, including the ovaries, are "masculinized" by exposure to hormones from the male twin through shared fetal circulation. Morphologically the ovary has varying degrees of masculinization, with more severe cases containing seminiferous tubule-like structures (Prepin et al. 1979, Harikae et al. 2012). The rare cases of freemartins observed in sheep are often heavily masculinized with seminiferous tubules and rudimentary epididymides although undifferentiated-type ovaries are also observed (Smith et al. 2003). Common to all morphological classification is the lack of follicles and resulting reproductive failure. Gonadal development and follicular formation has been examined in cattle freemartins. The very early stages of gonadal development are morphologically indistinguishable from normal female fetuses (Rajakoski \& Hafez 1964, Jost et al. 1972, Prepin et al. 1979). However, by day 60 of gestation, the gonads appear smaller than normal animals and mitosis of germ cells seemed slower (Rajakoski \& Hafez 1964, Jost et al. 1972, Prepin et al. 1979). Also, relatively fewer germ cells entered meiosis in freemartin females compared to control normal females. By birth all germ cells present in freemartin gonads disappear. In undifferentiated-type ovaries, the disappearance of the germ cells coincides with the end of germ cells entering meiosis in normal females whereas in ovaries with seminiferous tubules like structures the disappearance of the germ cells could be delayed a month (Prepin et al. 1979). Anti-Mullerian hormone has been identified as the hormone likely driving the observed changes in the freemartin ovary, likely through inhibition of germ cell proliferation (Vigier et al. 1987). The process of germ cell meiosis seems to be a key time point in the abnormalities observed in both freemartins and the Polled Intersex Syndrome in goats. Ground work to begin to understand this key developmental event has been provided by studies examining expression of key genes during this process (MandonPepin et al. 2003, Baillet et al. 2008), but further research is likely to bring additional insights.

Steroids have also been postulated to be involved in follicular formation as the developing ovary expresses receptors for various steroids (Juengel et al. 2006, Nilsson \& Skinner 2009, Burkhart et al. 2010, Garverick et al. 2010) and synthesizes progesterone, androgens and oestradiol (Shemesh 1980, Dominguez et al. 1988, Quirke et al. 2001, Yang \& Fortune 2008, Nilsson \& Skinner 2009). In particular, cells in the ovigerous cords express receptors for oestrogen, with both germ cells and pregranulosa cells expressing ESR2 and pregranulosa cells expressing ESR1 (Juengel et al. 2006, Burkhart et al. 2010, Garverick et al. 2010). This has led to the hypothesis that oestradiol may be involved in formation of the ovigerous cords and may be important for germ cell maturation and survival (Shemesh 1980, Dominguez et al. 1988, Juengel et al. 2002).

Progesterone is also thought to play a role in follicular formation as in vitro exposure to high levels of progesterone for two days resulted in a reduced number of formed follicles with more oocytes retained in the ovigerous cords (Nilsson \& Skinner 2009). Thus progesterone appears to regulate the timing of follicular formation but whether the number of follicles formed is regulated by progesterone is unclear. Interestingly, during the time of ovarian follicle formation in sheep, the classical nuclear progesterone receptor could not be detected using in situ hybridization (Juengel et al. 2006). However, mRNA encoding the surface membrane progesterone receptor PGRMC1 was present in fetal bovine ovaries during the time of follicle formation and thus the actions of progesterone may be mediated, at least in part, by the surface membrane progesterone receptor (Nilsson \& Skinner 2009).

Freemartin animals are exposed to increased levels of androgens from the male co-twin. Additionally, pregnant ewes have been experimentally treated with androgens to masculinize the reproductive tract of the female offspring. Exposure of ewe lambs in utero to high levels of either 
testosterone (thus potentially high levels of androgens and/or oestrogens) or dihydrotestosterone (DHT) between day 30 and 90 of gestation did not affect the numbers of germ cells present on day 90 of gestation or follicles on day 140 of gestation (Smith et al. 2009). However, other structures, particularly the mesonephric remnant, in the developing ovary were altered in the androgen-exposed animals. This was linked with increased recruitment of follicles into the growing pool (Smith et al. 2009). Thus, in sheep excess androgens/oestrogens do not appear to alter the number of follicles formed in vivo but are associated with increased recruitment during early post-natal life and thus accelerated depletion of the ovarian reserve (Padmanabhan et al. 2012). However, in vitro culture of pieces of cortical ovarian tissue from bovine fetuses with oestradiol, but not DHT, significantly reduced the number of follicles (Yang \& Fortune 2008, Fortune et al. 2013). The apparent inhibitory effect of oestrogen on follicle formation in vitro in bovine ovarian pieces contrasts with the lack of affect in sheep in vivo. This difference could be related to differences in timing of steroid administration, although in both cases, steroid exposure would be happening during early follicle formation. Alternatively, the differences could be related to the concentration of oestrogens, in vitro versus in vivo conditions, or differences between the two species.

\section{Conclusions}

Clearly, formation and development of the ovary and ovarian follicles is a highly orchestrated event requiring the coordination of multiple processes to ensure healthy oocytes are present for the female's reproductive lifespan. Perturbations in any of these processes can have subtle to catastrophic effects on the female's reproductive potential. Over the past decade or so, new insights have been gained regarding the process of formation of ovarian follicles in many species. A better understanding of the role of the epithelium (or GREL cells) as the source for the pregranulosa cells in the developing follicle as well as the major contribution of mesonephric derived cells to the developing architecture of the ovary has been gained. Recognition of the links between the processes surrounding follicle formation and the animal's future reproductive potential has begun with identification of some factors controlling formation of the ovarian follicles. Several key developmental events have been identified which can contribute to the number, and potentially the quality, of the ovarian follicles formed, such as germ cell proliferation, meiosis and apoptosis. However, how these processes are controlled remains a mystery. Current and future focus on the regulation of these key developmental events should bring additional insights into improving the lifetime reproductive potential of the animal.

\section{Acknowledgements}

The authors would like to thank Drs. Peter Hurst and Ray Rodgers for their insightful conversations on the topic. This work was funded by AgResearch Core funding provided by the New Zealand Ministry for Business, Innovation and Employment. 


\section{References}

Baillet A, Mandon-Pepin B, Cabau C, Poumerol E, Pailhoux E \& Cotinot C 2008 Identification of transcripts involved in meiosis and follicle formation during ovine ovary development. BMC Genomics 9436.

Bao B \& Garverick HA 1998 Expression of steroidogenic enzyme and gonadotropin receptor genes in bovine follicles during ovarian follicular waves: a review. Journal of Animal Science 76 1903-1921.

Baron D, Batista F, Chaffaux S, Cocquet J, Cotinot C, Cribiu E, De Baere E, Guiguen Y, Jaubert F, Pailhoux E, Pannetier M, Vaiman D, Vigier B, Veitia R \& Fellous M 2005 Foxl2 gene and the development of the ovary: a story about goat, mouse, fish and woman. Reproduction Nutrition Development 45 377-382.

Boulanger L, Kocer A, Daniel N, Pannetier M, Chesne P, Heyman Y, Renault L, Mandon-Pepin B, Chavatte-Palmer P, Vignon X, Vilotte JL, Cotinot C, Renard JP \& Pailhoux E 2008 Attempt to rescue sex-reversal by transgenic expression of the PISRT1 gene in XX PIS-/- goats. Sexual Development 2 142-151.

Burkhart MN, Juengel JL, Smith PR, Heath DA, Perry GA, Smith MF \& Garverick HA 2010 Morphological development and characterization of aromatase and estrogen receptors alpha and beta in fetal ovaries of cattle from days 110 to 250. Animal Reproduction Science 117 43-54.

Cushman RA, Allan MF, Kuehn LA, Snelling WM, Cupp AS \& Freetly HC 2009 Evaluation of antral follicle count and ovarian morphology in crossbred beef cows: investigation of influence of stage of the estrous cycle, age, and birth weight. Journal of Animal Science 87 1971-1980.

Da Silva P, Aitken RP, Rhind SM, Racey PA \& Wallace JM 2002 Impact of maternal nutrition during pregnancy on pituitary gonadotrophin gene expression and ovarian development in growth-restricted and normally grown late gestation sheep fetuses. Reproduction 123 769-777.

Da Silva P, Aitken RP, Rhind SM, Racey PA \& Wallace JM 2003 Effect of maternal overnutrition during pregnancy on pituitary gonadotrophin gene expression and gonadal morphology in female and male foetal sheep at day 103 of gestation. Placenta 24 248-257.

Dominguez MM, Liptrap RM \& Basrur PK 1988 Steroidogenesis in fetal bovine gonads. Canadian Journal of Veterinary Research 52 401-406.

Erickson B 1966 Development and Radio-Response of the Prenatal bovine ovary. Journal of Reproduction and Fertility 10 97-105.

Eriksson K 1943 Hereditary forms of sterility in Cattle: Lund Hakan Ohlssons Boktryckeri:155.

Evans AC, Mossa F, Walsh SW, Scheetz D, Jimenez-Krassel F, Ireland JL, Smith GW \& Ireland JJ 2012 Effects of maternal environment during gestation on ovarian folliculogenesis and consequences for fertility in bovine offspring. Reproduction in Domestic Animals 47 Suppl 4 31-37.

Fortune JE 2003 The early stages of follicular development: activation of primordial follicles and growth of preantral follicles. Animal Reproduction Science 78 135-163.
Fortune JE, Yang MY, Allen JJ \& Herrick SL 2013 Triennial Reproduction Symposium: the ovarian follicular reserve in cattle: what regulates its formation and size? Journal of Animal Science 91 3041-3050.

Fowler PA, Dora NJ, McFerran H, Amezaga MR, Miller DW, Lea RG, Cash P, McNeilly AS, Evans NP, Cotinot C, Sharpe RM \& Rhind SM 2008 In utero exposure to low doses of environmental pollutants disrupts fetal ovarian development in sheep. Molecular Human Reproduction 14 269-280.

Garverick HA, Juengel JL, Smith P, Heath DA, Burkhart MN, Perry GA, Smith MF \& McNatty KP 2010 Development of the ovary and ontongeny of $\mathrm{mRNA}$ and protein for P450 aromatase (arom) and estrogen receptors (ER) alpha and beta during early fetal life in cattle. Animal Reproduction Science 117 24-33.

Harikae K, Tsunekawa N, Hiramatsu R, Toda S, Kurohmaru M \& Kanai Y 2012 Evidence for almost complete sex-reversal in bovine freemartin gonads: formation of seminiferous tubule-like structures and transdifferentiation into typical testicular cell types. Journal of Reproduction and Development 58 654-660.

Hatzirodos N, Nigro J, Irving-Rodgers HF, Vashi AV, Hummitzsch K, Caterson B, Sullivan TR \& Rodgers RJ 2012 Glycomic analyses of ovarian follicles during development and atresia. Matrix Biology 31 45-56.

Hirshfield AN 1991 Theca cells may be present at the outset of follicular growth. Biology of Reproduction 44 1157-1162.

Honda A, Hirose M, Hara K, Matoba S, Inoue K, Miki H, Hiura H, Kanatsu-Shinohara M, Kanai Y, Kono T, Shinohara T \& Ogura A 2007 Isolation, characterization, and in vitro and in vivo differentiation of putative thecal stem cells. Proceedings of the National Academy of Sciences, USA 104 12389-12394.

Hummitzsch K, Irving-Rodgers HF, Hatzirodos N, Bonner W, Sabatier L, Reinhardt DP, Sado Y, Ninomiya Y, Wilhelm D \& Rodgers RJ 2013 A new model of development of the mammalian ovary and follicles. PLOS ONE 8 e55578.

Ireland J, Zielak-Steciwko AE, Jimenez-Krassel F, Folger J, Bettegowda A, Scheetz D, Walsh S, Mossa F, Knight PG, Smith GW, Lonergan P \& Evans AC 2009 Variation in the ovarian reserve is linked to alterations in intrafollicular estradiol production and ovarian biomarkers of follicular differentiation and oocyte quality in cattle. Biology of Reproduction 80 954-964.

Jost A, Vigier B \& Prepin J 1972 Freemartins in cattle: the first steps of sexual organogenesis. Journal of Reproduction and Fertility 29 349-379.

Juengel JL, Sawyer HR, Smith PR, Quirke LD, Heath DA, Lun S, Wakefield SJ \& McNatty KP 2002 Origins of follicular cells and ontogeny of steroidogenesis in ovine fetal ovaries. Molecular and Cellular Endocrinology 191 1-10.

Juengel JL, Bodensteiner KJ, Heath DA, Hudson NL, Moeller CL, Smith P, Galloway SM, Davis GH, Sawyer HR \& McNatty KP 2004 Physiology of GDF9 and 
BMP15 signalling molecules. Animal Reproduction Science 82-83 447-460.

Juengel JL, Heath DA, Quirke LD \& McNatty KP 2006 Oestrogen receptor alpha and beta, androgen receptor and progesterone receptor mRNA and protein localisation within the developing ovary and in small growing follicles of sheep. Reproduction 131 81-92.

Juengel JL, Davis GH \& McNatty KP 2013 Using sheep lines with mutations in single genes to better understand ovarian function. Reproduction 146 R111-123.

Lea RG, Andrade LP, Rae MT, Hannah LT, Kyle CE, Murray JF, Rhind SM \& Miller DW 2006 Effects of maternal undernutrition during early pregnancy on apoptosis regulators in the ovine fetal ovary. Reproduction 131 113-124.

Logan KA, Juengel JL \& McNatty KP 2002 Onset of steroidogenic enzyme gene expression during ovarian follicular development in sheep. Biology of Reproduction 66 906-916.

Lundy T, Smith P, O'Connell A, Hudson NL \& McNatty KP 1999 Populations of granulosa cells in small follicles of the sheep ovary. Journal of Reproduction and Fertility 115 251-262.

Mandon-Pepin B, Oustry-Vaiman A, Vigier B, Piumi F, Cribiu E \& Cotinot C 2003 Expression profiles and chromosomal localization of genes controlling meiosis and follicular development in the sheep ovary. Biology of Reproduction 68 985-995.

McNatty KP, Fidler AE, Juengel JL, Quirke LD, Smith PR, Heath DA, Lundy T, O'Connell A \& Tisdall DJ 2000 Growth and paracrine factors regulating follicular formation and cellular function. Molecular and Cellular Endocrinology 163 11-20.

Mork L, Maatouk DM, McMahon JA, Guo JJ, Zhang P, McMahon AP \& Capel B 2012 Temporal differences in granulosa cell specification in the ovary reflect distinct follicle fates in mice. Biology of Reproduction 8637.

Mossa F, Walsh SW, Butler ST, Berry DP, Carter F, Lonergan P, Smith GW, Ireland JJ \& Evans AC 2012 Low numbers of ovarian follicles $>/=3 \mathrm{~mm}$ in diameter are associated with low fertility in dairy cows. Journal of Dairy Science 95 2355-2361.

Mossa F, Carter F, Walsh SW, Kenny DA, Smith GW, Ireland JL, Hildebrandt TB, Lonergan P, Ireland JJ \& Evans AC 2013 Maternal undernutrition in cows impairs ovarian and cardiovascular systems in their offspring. Biology of Reproduction 8892.

Murdoch WJ, Van Kirk EA, Vonnahme KA \& Ford SP 2003 Ovarian responses to undernutrition in pregnant ewes, USA. Reproductive Biology and Endocrinology 16.

Nilsson EE \& Skinner MK 2009 Progesterone regulation of primordial follicle assembly in bovine fetal ovaries. Molecular and Cellular Endocrinology 313 9-16.

Padmanabhan V, Smith P \& Veiga-Lopez A 2012 Developmental programming: Impact of prenatal testosterone treatment and postnatal obesity on ovarian follicular dynamics. Journal of Developmental Origins of Health and Disease 3 276-286.

Padula AM 2005 The freemartin syndrome: an update. Animal Reproduction Science 87 93-109.
Pailhoux E, Vigier B, Chaffaux S, Servel N, Taourit S, Furet JP, Fellous M, Grosclaude F, Cribiu EP, Cotinot C \& Vaiman D 2001a A 11.7-kb deletion triggers intersexuality and polledness in goats. Nature Genetics 29 453-458.

Pailhoux E, Vigier B, Vaiman D, Schibler L, Vaiman A, Cribiu E, Nezer C, Georges M, Sundstrom J, Pelliniemi LJ, Fellous M \& Cotinot C 2001b Contribution of domestic animals to the identification of new genes involved in sex determination. Journal of Experimental Zoology 290 700-708.

Pailhoux E, Vigier B, Vaiman D, Servel N, Chaffaux S, Cribiu EP \& Cotinot C 2002 Ontogenesis of female-tomale sex-reversal in XX polled goats. Developmental Dynamics 224 39-50.

Pannetier M, Fabre S, Batista F, Kocer A, Renault L, Jolivet G, Mandon-Pepin B, Cotinot C, Veitia R \& Pailhoux E 2006 FOXL2 activates P450 aromatase gene transcription: towards a better characterization of the early steps of mammalian ovarian development. Journal of Molecular Endocrinology 36 399-413.

Prepin J, Vigier B \& Jost A 1979 Meiosis in fetal freemartin gonads and in rat fetal ovaries in vitro. Annales de Biologie Animale, Biochimie, Biophysique 19 12631271.

Quirke LD, Juengel JL, Tisdall DJ, Lun S, Heath DA \& McNatty KP 2001 Ontogeny of steroidogenesis in the fetal sheep gonad. Biology of Reproduction 65 216-228.

Rae MT, Palassio S, Kyle CE, Brooks AN, Lea RG, Miller DW \& Rhind SM 2001 Effect of maternal undernutrition during pregnancy on early ovarian development and subsequent follicular development in sheep fetuses. Reproduction 122 915-922.

Rae MT, Kyle CE, Miller DW, Hammond AJ, Brooks AN \& Rhind SM 2002 The effects of undernutrition, in utero, on reproductive function in adult male and female sheep. Animal Reproduction Science 72 63-71.

Rajakoski E \& Hafez ES 1964 Cytological Differentiation of Fetal Bovine Gonads. Cytogenetics 3 193-200.

Reader KL, Haydon LJ, Littlejohn RP, Juengel JL \& McNatty KP 2012 Booroola BMPR1B mutation alters early follicular development and oocyte ultrastructure in sheep. Reproduction, Fertility and Development 24 353-361.

Reynaud K \& Driancourt MA 2000 Oocyte attrition. Molecular and Cellular Endocrinology 163 101-108.

Ruoss C, Tadros A, O'Shea T, McFarlane J \& Almahbobi G 2009 Ovarian follicle development in Booroola sheep exhibiting impaired bone morphogenetic protein signalling pathway. Reproduction 138 689-696.

Santos-Biase WK, Biase FH, Buratini J, Jr., Balieiro J, Watanabe YF, Accorsi MF, Ferreira CR, Stranieri P, Caetano AR \& Meirelles FV 2012 Single nucleotide polymorphisms in the bovine genome are associated with the number of oocytes collected during ovum pick up. Animal Reproduction Science 134 141-149.

Sawyer HR, Smith P, Heath DA, Juengel JL, Wakefield SJ \& McNatty KP 2002 Formation of ovarian follicles during fetal development in sheep. Biology of Reproduction 66 1134-1150. 
Settergren I 1964 The Ovarian Morphology in Clinical Bovine Gonadal Hypoplasia with some aspects of its Endocrine Relations. Stockholm: Acta Veterinaria Scandinavica 108.

Shemesh M 1980 Estradiol-17 beta biosynthesis by the early bovine fetal ovary during the active and refractory phases. Biology of Reproduction 23 577-582.

Smith KC, Parkinson TJ, Pearson GR, Sylvester L \& Long SE 2003 Morphological, histological and histochemical studies of the gonads of ovine freemartins. Veterinary Record 152 164-169.

Smith P, O WS, Hudson NL, Shaw L, Heath DA, Condell L, Phillips DJ \& McNatty KP 1993 Effects of the Booroola gene (FecB) on body weight, ovarian development and hormone concentrations during fetal life. Journal of Reproduction and Fertility 98 41-54.

Smith P, Braw-Tal R, Corrigan K, Hudson NL, Heath DA \& McNatty KP 1994 Ontogeny of ovarian follicle development in Booroola sheep fetuses that are homozygous carriers or non-carriers of the FecB gene. Journal of Reproduction and Fertility 100 485-490.

Smith P, Steckler TL, Veiga-Lopez A \& Padmanabhan V 2009 Developmental programming: differential effects of prenatal testosterone and dihydrotestosterone on follicular recruitment, depletion of follicular reserve, and ovarian morphology in sheep. Biology of Reproduction 80 726-736.

Tanaka Y, Nakada K, Moriyoshi M \& Sawamukai Y 2001 Appearance and number of follicles and change in the concentration of serum FSH in female bovine fetuses. Reproduction 121 777-782.

Venhoranta H, Pausch H, Wysocki M, Szczerbal I, Hanninen R, Taponen J, Uimari P, Flisikowski K, Lohi H, Fries R, Switonski M \& Andersson M 2013 Ectopic KIT Copy Number Variation Underlies Impaired Migration of Primordial Germ Cells Associated with Gonadal Hypoplasia in Cattle (Bos taurus). PLOS ONE 8 e75659.

Vigier B, Watrin F, Magre S, Tran D \& Josso N 1987 Purified bovine AMH induces a characteristic freemartin effect in fetal rat prospective ovaries exposed to it in vitro. Development 100 43-55.

Wang J \& Roy SK 2004 Growth differentiation factor-9 and stem cell factor promote primordial follicle formation in the hamster: modulation by follicle-stimulating hormone. Biology of Reproduction 70 577-585.

Wrobel KH \& Suss F 1998 Identification and temporospatial distribution of bovine primordial germ cells prior to gonadal sexual differentiation. Anatomy and Embryology 197 451-467.

Yang MY \& Fortune JE 2008 The capacity of primordial follicles in fetal bovine ovaries to initiate growth in vitro develops during mid-gestation and is associated with meiotic arrest of oocytes. Biology of Reproduction $\mathbf{7 8}$ 1153-1161.

Young JM \& McNeilly AS 2010 Theca: the forgotten cell of the ovarian follicle. Reproduction 140 489-504. 
